\title{
Engaging Multiliteracies Learning
}

\author{
Terry Loerts, Christina Belcher \\ Redeemer University College \\ Canada
}

\begin{abstract}
This study follows teacher candidates through their first year of teaching, tracking their understandings and implementations of multiliteracies pedagogy. The purpose of the study is to ask whether first year teachers implement what they are taught, or rely on previous or modeled experience when they enter the teaching profession. Our main research question explores if and why multimodal literacies are implemented in early teaching practice. New teachers were invited to participate by email, and their response provided consent. Upon responding, participants were supplied with a questionnaire. Using a lens of multiliteracies and multimodality, responses were analyzed using a Modified Constant Comparative Method. Indications in the data reveal difficulties and opportunities when applying multiliteracies pedagogy. The findings enhance limited research in this area. Perceived benefits for education are to inform pedagogy, create more equitable teaching and learning environments, and promote professional reflective practices. These enhance learning within a multiliteracies framework.
\end{abstract}

\section{Introduction}

This qualitative research builds upon a previously completed pilot study in the area of teacher candidates' conceptions of literacy. This earlier study examined how teacher candidates' conceptions of literacy might be impacted by including print and non-print modes of communication through the use of visual journaling as a form of reflective practice. Students interacted and reflected on course teachings and previously completed student teaching experiences while they considered how they linked to specific learning expectations laid out by the Ontario Ministry of Education in different subject areas. From such reflection, they crafted visual multimodal artifacts with a balance of approximately $50 \%$ visual and $50 \%$ print which was intended to challenge students to think about how they could communicate their intended meanings through various visual modes and media. To many, this was the first time they had encountered the opportunity or the freedom to do so. The visual artefacts were learning opportunities for the teacher candidates and represented significant application of knowledge and understanding about topics in literacy learning after much classroom discussion, modelling, and learning about the affordances of modes and media. In this way we sought to honour the theoretical underpinnings of multiliteracies and multimodal literacy learning [1] - the foundational concepts for our present research study on multiliteracies learning with first year teachers.

We thought it would be interesting to build on this previous pilot study to see the difference between the kinds of reflective practices that occurred when these participants were students in the classroom and then transferring that practice to their teacher-as-reflective-practitioner stance. The findings of our previous pilot study highlighted that teacher candidates not only embraced the chance to be creative, they also valued ways in which they could represent knowledge in modes not normally allowed in academia. This was perceived as a valuable experience. Themes included creativity, engagement, identity, developing multiliteracies understanding, and emerging conceptions of pedagogy behind the creation of multimodal texts. This pilot study provided a segue into teaching and learning within the classroom from a multiliteracies pedagogical lens for the present study.

\section{Research Objectives}

Our current research follows teacher candidates through their first year of teaching where we sought to answer the following research questions: As a first year teacher, how has a pedagogy of multiliteracies informed how you teach? Have you implemented any particular pedagogies into your teaching to facilitate components of multiliteracies, specifically 
multimodal literacy learning? If so, how are these assessed and/or evaluated? In following teachers from their teacher education program into their first year of teaching, this research endeavors to shed light into how theory does or does not translate into practice. Not only does this benefit the teaching profession to improve course content in the area of literacy, it also serves to involve first year teachers in reflective practice as a way to continue their learning about multiliteracies. This study fills a gap in the research literature in understanding how institutions of higher learning can benefit from the kinds of reflective practice questions that we are asking first year teachers about implementing a pedagogy of multiliteracies.

\section{Theoretical Perspectives}

This study takes place in Ontario and utilizes the theoretical perspectives of multiliteracies [1] and multimodal literacy [2]. Because the participants are previous teacher candidates in a Bachelor of Education program where we teach, they were introduced to literacy practices commensurate with those found in the public system from the Ontario Ministry of Education (OME) during their course of studies. As such, participants were familiar with curriculum documents that outlined definitions of literacy which led to in-class discussions of multiliteracies and multimodal literacy - two terms that are not clearly explained within the present Ontario curriculum documents. To elucidate a clearer understanding of multimodal literacy and multiliteracies as the theoretical lenses used in this study, it is helpful to first understand what literacy is defined as within the Ontario context. The OME defines literacy as, "The ability to use language and images in rich and varied forms to read, write, listen, speak, view, represent, and think critically about ideas. It enables us to share information, to interact with others, and to make meaning. Literacy is a complex process that involves building on prior knowledge, culture, and experiences in order to develop new knowledge and deeper understanding. It connects individuals and communities, and is an essential tool for personal growth and active participation in a democratic society." [3] This definition of literacy served as the basis for further in-class discussions when we were teaching these previous teacher candidates about what the various forms of literacy could look like within classroom teaching, how they could enhance student learning, and how they aligned with $21^{\text {st }}$ century understandings of what it means to be literate. As educators, we felt that the current definition of literacy within the curriculum documents for Ontario did not go far enough to articulate an expanded understanding of literacy as promoted by the theoretical concepts of multiliteracies and multimodal literacy. Our research conclusions have supported this assumption. Our classes essentially equipped the teacher candidates with the theoretical and practical knowledge of literacy learning as defined by these perspectives in an effort to help them apply this understanding as they started their own teaching careers. This is the premise from which we built our present study - to follow these participants in their first year of teaching to see if they implemented a pedagogy of multiliteracies.

Multiliteracies [1] is defined as a cultural process where people learn to communicate in multimodal ways which are often reflective of the culture in which they are living. The premise of multiliteracies is that literacy is much more than being able to read and write. Because there has been what Jewitt calls a "social and cultural reshaping of the communicational landscape," [4] linguistic forms of communication such as reading and writing are no longer solely adequate for communication. One of the foundational papers written about this reshaping of communication is by the New London Group (NLG) in 1996. Their paper, A Pedagogy of Multiliteracies: Designing Social Futures [1] talks about global and linguistic diversities that people utilize in their everyday lives. This includes the variety of texts that people use in their every day practices that include print-based literacies and the visual and multimodal texts that can be created through various mediums (e.g. through technology). The NLG further explain the variety of texts that can be created and how they are multimodal in nature. This brings the second theoretical perspective to light - that of multimodal literacy.

Multimodal literacy defines literacy in an expanded way that goes beyond traditional reading and writing practices that dominate school literacy learning [7]. It takes into account all modes of communication including image, gaze, gesture, movement, music, speech, and sound effect [2]. Multimodal literacy also considers how these modes are read, viewed, produced, responded to and understood [5] - whether through technological means or more print-based mediums such as film, music compositions, music, or pen and paper. Jewitt [4] says it well when she says that communicating in multimodal ways is "embedded within a wider social semiotic" and does not "side-line language." In multimodal literacy learning, each mode is considered equal in importance, even if every mode does not have comparable representation in a text.

The idea the multimodal literacy enables individuals to be active in designing meaning speaks to the agentive nature of being literate. The design process also enables the designer to be engaged, process information critically and creatively, encourages imagination and problem solving, and to be self-reflective [6]. The concern that we have as educators, and one that is reflected in the research 
literature, is that multimodal literacy learning is complex and essential in today's communicational landscape. These literacy practices are sometimes acknowledged in school settings, but more often they are not [7].

Multimodal literacy as a construct is relatively young. It has been theorized for a few decades and researchers continue to advocate an expanded view of literacy to take into account all modes of communication and the many ways these multimodal texts can be read, viewed, produced, responded to, and understood [4, 5]. The way that modes are understood and implemented to create meaning is multifaceted. The ways that schools affirm or ignore these potentially meaningful modes of communication will shape the kinds of texts that students make, view, respond to and understand. These are foundational frameworks on which to base our work in guiding teacher candidates to further their understanding and application of multiliteracies pedagogy in their own teaching.

\section{Literature Review}

The significance of this research comes at a time where tensions still exist in educational contexts for what counts as literacy. This landscape is more multimodal in nature [2], reflecting the need to provide an expanded understanding and application of literacy and the media through which we communicate. Recent research indicates educational policies and standardized testing in Ministry guidelines for Ontario focus on print-based texts [8]. Cummins [9] questions the effectiveness of multiliteracies within various educational systems from schools through to the Ontario Ministry of Education. The research literature indicates that print-based literacy learning is still dominant in many classrooms [8, 11]. These tensions spill over into teacher education programs as theory does not always translate into practice for helping teacher candidates feel "more confident of their ability to deal with multimodal materials" [8]

This reshaping of the communicational landscape is in part a response to the findings of the NLG [1]. The authors suggest that global and linguistic diversities fuel the variety of texts people use to communicate. They also propose that literacy pedagogy should reflect facility with these texts in multimodal ways. Thus, a pedagogy of multiliteracies emerged to represent "a different kind of pedagogy, one in which language and other modes of meaning are dynamic representational resources, constantly being remade by their users as they work to achieve their various cultural purposes" [1]. Providing ways for teacher candidates to think about teaching and learning through multimodal literacy opportunities does not replace, as much as it expands and enhances traditional linguistically based pedagogies. Various studies in the research literature point to the teaching and learning opportunities and outcomes provided from a multiliteracies perspective at both the university and K-12 education levels.

One research project that exemplified the possibilities that can happen with multimodal literacy learning occurred with grade one and two students in a South African school. Entitled the Olifantsvlei Fresh Stories Project [11] the students developed stories in multimodal ways - through the use of paper mâché dolls, play performances, drawings, writing, and dialogue. The project enabled students to be creatively engaged with their own knowledge and resources to become active designers of meaning. Unexpected setbacks with the paper mâché mixture propelled students to insist that they could find their own resources from home to fashion their own dolls. The resulting traditional African figures that the students went on to fashion with the help of family members included various recyclable and natural materials such as food containers, gourds, grass, and cloth. Stein [11] argues that these are unexpected moments of creativity that serve as further entry points for literacy learning.

In a research study by Winters and Lenters [12] grade five students engaged in dramatic storytelling using fairytales. Students began by reading traditional fairytales which they then elaborated on from their own experiences and versions specific to their own cultural backgrounds. They searched for alternate versions through book trailers, videos and DVD's and then compiled a list of elements that were similar throughout different genres before getting into groups to create their own dramatic fairytale. They viewed live performances and had discussions about how they would use speech, gesture, space, and simple props to communicate. Throughout this process students discovered the affordances of modes and their effectiveness at communicating intended meaning. Throughout the process of rehearsing and receiving feedback from peers, teachers, and a professional theatre group, the students continued to refine their written scripts and dramatic productions which were eventually videotaped and viewed by the whole class. These multimodal literacy learning experiences afforded students multiple ways to "explore and experiment with language" [12].

Research with graduate students as practicing classroom teachers also engaged in multimodal design processes to create multimodal literacy texts [13]. The experiences of actively engaging with different modes and media served as a model for practices that they could bring back to their own classrooms. In an assignment called a Multimedia Life Box Project, the students created a multimodal text that reflected something personal in their lives. One student tried to convey her experiences through a visual presentation where words dominated, but 
through her editing process she recognized that words were not providing the affordances of her experiences with spelunking in a way that conveyed her adventurous and terrified feelings. Experimenting with other modes led her to investigate the affordances of sounds and images. She found a sound of a fast heartbeat to include in the background of her text that reflected her feelings of claustrophobia that she constantly fought to overcome while exploring caves. The affordance of sound conveyed a more physical reality to her experiences. From these design processes the student recognized the importance of experimenting with modes and media and providing resources with which to design and communicate in multimodal ways.

These brief examples provide a glimpse into the potential of multimodal literacy learning that is not yet fully realized in classrooms [14]. Identifying how new teachers translate multiliteracies pedagogy into their first year of teaching practice may provide further insight and contribute to this type of research literature.

\section{Methodology}

This research was undertaken following ethical approval by Redeemer University College. Recent teacher education graduates active in teaching were invited to participate in an online questionnaire. The participant pool of 38 graduates included those who were employed either full or part time. Following invitation, $18 \%$ volunteered for the study. Students were contacted through email inviting them to participate in the research. After emailing back their consent, they were sent the questionnaire. All eligible participants were informed about their roles and rights. The questionnaire explored how multiliteracies education in an undergraduate program affects the teaching of recently graduated teacher candidates. It also asked the participants how their pre-service education is given value within the teacher's first year of teaching in the classroom.

Questions were asked from both a teaching and learning perspective to consider how those new to the profession utilized multiliteracies in their practice. The participants, as first year teachers, were asked to reflect on their teaching practices by thinking about how a multiliteracies perspective may or may not shape their teaching. Sample questions included: Have you given students opportunities to express their learning and communicate in multimodal ways? If so, describe. In thinking about lessons that have utilized a multiliteracies perspective, how do you assess or evaluate assignments? If thinking about implementing multiliteracies pedagogy is difficult, what hinders this? Can you explain why you think these difficulties may influence your teaching?
The responses to the questionnaire were analyzed using a Modified Constant Comparative Method (MCCM) [15]. This method builds on the work of Glaser and Strauss [16] where data that is collected is examined and categorized according to emerging similarities in the data which are then coded. The insights from the initial examination of the data drives further data collection, categorization and coding. Eventually all data that is deemed relevant to the research question is coded; incongruent data is not used if it does not fit. The modification of the Constant Comparative Method allows for complexities in the data to be put into more than one category, allowing data to be coded in multiple ways. As a result the possible interconnectedness of the data is retained. The MCCM is a relatively new method for analyzing data in literacy research, and this study suggests how this method is particularly effective for elucidating the findings because of how the interconnectedness of the data is maintained.

As a MCCM, we analyzed our data using the process mentioned above. The responses to the questionnaire were charted, and then analyzed for individual perception. They were then reviewed to consider general participant group perceptions by similarity for each question, then were again reviewed and summarized for consistency and incongruences.

The process by which we analyzed our data unfolded like this: first, as participants responded to the questions posed, they were provided with pseudonyms and the reflective responses were charted by individual question and individual participant to each of the three questions posed. Second, charts were made of these responses. Third the data was then scrutinized for core words and ideas from each participant's response. Fourth, the data was reviewed again across the three questions for each individual's responses to see if identified ideas carried through across the three questions or if new information emerged. Fifth, the data was then reviewed to see the themes emerging from all collective participants for each question. From these analyses, we found similarities, differences and possible insights on the research as a whole.

\section{Findings and Discussion}

In the questionnaire responses, there were two themes that dominated the findings. We categorized the first theme as the opportunities or difficulties that the participants noted, from their perspective, in applying multiliteracies pedagogy. Data revealed that the first year teachers did see opportunities to enhance the curriculum as some saw literacy through a cultural lens while others saw multiliteracies as more of a strategy so students could have a variety of entry points to learning. Some opportunities as well as difficulties lay within the interpretation of the use 
of technology, while others understood multiliteracies as a means for providing other modes of communication to enhance student learning. In the second theme that we categorized as student learning and assessment practices, the participants noted that their pedagogical practices focused on holistic learning as well as instances of learning how to learn. This was especially noted by some instances in the findings with multimodal literacy learning. Finally, assessment practices were seen in various ways by the participants - some saw assessments as more self-directed learning while others noted that assessment should be more than just a final product so that students would feel comfortable exploring new ideas. These findings are presented below along with discussion.

In being attentive to "the voices of the everyday" [17] in participant narratives coding resulted in the two overarching key themes of opportunities and difficulties. Responses to the first theme can be understood in what value these participants place on multiliteracies, how multiliteracies is defined, and how that term is understood. The aspect of comprehending the scope of multiliteracies learning became significant as it illuminated the depth or lack of understanding that the participants had about implementing a pedagogy of multiliteracies. In addition, the findings also provided the researchers information conducive to reflective practice for future teaching. Selected samplings of participant responses are included in the following section in order to provide a variety of participant interpretations and perceptions of multiliteracies knowledge and understanding. Where possible the exact wording of the participant responses were used as a way of honouring their voices [18] and to further contribute to the integrity of the research.

One of the participants, Melody, voiced the insight that any new pedagogy or content specific terminology lays out a foundation for shaping lessons from a directive or perspective. "The multiliteracies perspective has also influenced me in that I am more aware of the cultural lens through which we see our study topics." For Melody, it is significant to note that multiliteracies have a cultural ecology, and are more than a method. She sees multiliteracies as more perspectival than strategic. This aligns well with the definition of multiliteracies at the beginning of this study that described how multiliteracies is a cultural process. Essentially, culture is constantly changing, so teaching is also reflective of those changes in some ways.

In contrast, Jane sees multiliteracies as a "methodology or strategy" which supports diversity by allowing multiple activities according to the strengths of the students. In effect Jane sees multiliteracies as a strategy where students are able to have a variety of entry points to learning. She notes: "I do not believe it is effective to focus on one aspect of language (written or spoken), but try to include multiple teaching methods and activities." Jane also noted that she perceives multiliteracies as being aligned with specific subjects, most notably with English Language Arts (ELA). While multiliteracies may often be associated predominantly with ELA, the fundamental opportunities that exist go beyond subject specific areas; ideally they need to be thought of as more fluid and interconnected within all subject areas. This is something that is important for both student engagement and teacher pedagogy.

Therese sees multimodal pedagogy as an opportunity from the standpoint that it is "a venue for implementing technology, new programs and apps into the classroom." She states: "By using photos, videos, they [students] are able to express what they are thinking without having to actually say it." Therese gets at the medium for the modal affordances that communicate. Her quote about photos is actually right on. However, we can have issue with her stance as a "venue for implementing technology" as this does not communicate understanding of the theoretical underpinnings - she does not have the metalanguage to show that she inherently understands the purpose of multiliteracies. Students do benefit from technology, but in a multiliteracies framework, technology is a tool to be used for understanding how different media can be used to create and understand multimodal texts. The affordances of technology can be advantageous in creating and viewing multimodal texts, but this is something that needs to be explicitly taught by the teacher so the students can apply this knowledge and learn what works to best communicate their intended meaning.

Joy adds a valuable perspective of the opportunities that multiliteracies can provide in the classroom. She teaches in a gender specific International School that uses Ontario Curriculum expectations. Due to an intentional institutional focus on pen and paper, she sees other modes of communication as being essential in the classroom for student learning. "This [school] program has various parts that do incorporate multimodal literacy, such as having the students use images to tell their thoughts or stories, incorporating the use of comic strip design ...in order to plan out their full writing piece." For Joy, the aspects of image and oral expression from different media are central, but not linked to any specifically owned technology. This may prove an interesting support to Melody's idea of multiliteracies as being a cultural ecology, which is truer to the purpose of multiliteracies learning.

One of our participants contributed her ideas of multiliteracies learning from the perspective of an occasional teacher. Sue did not have many opportunities to have her own classroom on a prolonged basis. She notes that in classrooms she 
frequents "there still seems to be a primary emphasis on more traditional reading and writing and less focus on other modes of literacy learning." This supports findings previously noted in the literature review. Sue had some flexibility in what she taught and as she noted, "I try to offer students freedom to express their ideas in different ways, though truthfully I do not have multiliteracies at the forefront of my mind." This raises an interesting thought: if teacher candidates graduate and do not have opportunities right away to enter a classroom, will they become what they have seen and experienced instead of applying what they have been taught when they do acquire a full-time job? Although Sue says her philosophy is more multimodal, her understanding on how to implement multimodal literacy is lessened by her perception of having inconsistent opportunities to do so because of her occasional teaching.

In reviewing these narratives on what the participants have seen as opportunities for multiliteracies learning, it became evident that although most of the newly minted teachers were enthusiastic in their pre-service teacher education to implement multiliteracies pedagogy, they did not fully understand how to implement multiliteracies in their classrooms until they had opportunity to reflect on what they would do to teach it. Perhaps in the transition from student to teacher there needs to be more opportunity for reflective practice. The findings indicate that support would certainly be helpful in this regard to solidify some of the understandings that were part of their literacy learning. At the same time it is helpful for us as educators to keep in mind that the emphasis must be on the learning that results from a multiliteracies perspective so that teachers see multiliteracies as more than just a strategy.

This concept on the focus on teaching and/or learning naturally surfaced in what we found to be the second key theme. This theme considered student learning and the value of multiliteracies in learning acquisition, including both assessment and any hindrances noted.

Melody clearly states what value she sees in multimodal literacies for the benefit of learning. "A multiliteracies perspective allows the student to learn about these literacies and how to examine them, learn from them, and use them properly. This is becoming more and more important as the global world becomes more prevalent and media plays an ever-increasing role in society." This is a very interesting response. In seeing the cultural ecology of multiliteracies as being more than a method, Melody appears to be able to reflect that education has a perspective, and this allows her to see what she will accept or reject as she teaches. Her assessments of tasks that include multimodal literacy learning involve not just the final texts which are assessed with the aid of a rubric, but also include collaboration, comprehension, creativity, and conferencing. As Melody explained, this allowed her to "find out, and explain back to them what their project has shown me, both strengths and areas of growth [or challenge]." Melody's aim for student learning was more holistic and her assessment was not just individually based. Melody noted that her teaching involved a collaborative discussion which allowed students to learn how to listen to the perspectives of others as well as to achieve individually. At the same time that Melody focused on these important aspects of multiliteracies learning, she indicated that it was a struggle to do so because time was such a factor for her - she seemed to never have enough time to do everything she really wanted to do. This was indicated in her comment where she said she struggled with "...how to make learning authentic while still being responsive to the curriculum." This is a common conundrum which was referenced by many participants and is not exclusive just to first year teachers [8].

Jane indicated in her questionnaire response that she sees learning as a "whole perspective." However, she seems to fragment her understanding of multiliteracies. She feels "a variety in techniques used reaches more students" and that "multiliteracies also pushes students to try different things and consider the world as diverse." However, as indicated by multiliteracies, learning is not just a technique. She admits that implementing multiliteracies pedagogy is hard and requires a "broader way of teaching and thinking." Jane says she is hindered by being "limited right now in my use of technology in the classroom because it is not available at my school." This seems to be a common misconception with participants who appear to be equating technology as multiliteracies learning, when it is considered only one aspect of a broader conceptualization of what multiliteracies learning can be in a classroom.

Similar sentiments are echoed by Sue who says that "using technology responsibly and effectively should be components of literacy teaching and students should be taught the value of this kind of multimodal approach." We agree that technology is a tool or medium through which modes are enacted. Sue is able to articulate this more effectively when she indicates a responsive use of technology. However, like Jane, she also seems to equate technology with a "multimodal approach" which indicates that she is still becoming aware of the possibilities of multiliteracies learning through technology. But it should not end there.

Therese sees the values of options as being what is most significant to multiliteracies learning. For example, when Therese wrote about her ideas of assessment, she mentioned that her students created their own rubrics and set their own standards of 
learning for themselves when they created multimodal texts. The students also presented their multimodal texts to each other in class. The way Therese put it, "Going above and beyond by using technology or a new method that they have not tried before will give them a level four." A level four is considered the achievement of the standard at a high proficiency. It seems as if Therese is looking at learning from the point of view of personal growth and achievement. She says herself that her biggest challenge is "pushing those students to use multimodal ways of learning." When students have experimented with different ways of learning and have mastered the specifics of particular modes or media, the rubric that they have created for themselves affirms their work. On the one hand, multiliteracies learning affirms student choice in the modes and media that they use to communicate their ideas effectively. Yet, there is also another aspect of this creativity and experimenting with modes and media - what exactly is being assessed? Although it is not clear from the questionnaire what it was that the students were assessing themselves on, it is important to note that within a theory of multiliteracies learning, assessment is most effective when it is holistic and looks at all modes and media and how they have been used. This begs the question - have the students from this teacher been taught about the affordances of modes and media for their presentations? Do students have facility with the possibilities and constraints of certain modes so that they are able to experiment and have a process of learning that affirms their choices or provides alternate ways of communicating their understanding? Theresa does not indicate that she clearly understands the essence of multiliteracies learning, and, like some other participants, seems to equate multiliteracies as a method more than a way of knowing. These questions surrounding the assessment of multimodal texts are also echoed in the research literature [7, 19]. These questions are something to consider further in order to fully affirm the possibilities of multiliteracies learning.

In summarizing these narratives for student learning and assessment, it is evident that these new teachers feel an urge to adopt a multiliteracies perspective in their work, although their understandings of how to do so vary greatly. The participants voiced both the perceived opportunities and problems that go along with applying newly acquired knowledge about multiliteracies learning. They also provide moments of their quandaries of how to assess texts that are multimodal in nature. Their concern appears to be about what purposeful learning will occur, and how will they find time to plan well for meaningful implementation. It is evident from the participant responses that the idea of assessing new multimodal texts is weaker than the enthusiasm to embrace a new mode. Some of the first year teacher's experiences may rest on how the first perceptions of multiliteracies were encountered, or in their interpretations of understanding multiliteracies as a 'way of knowing,' or as a way of using technology, or even a way of making a child more of a teacher to self as new ideas enter education. Perhaps, as the research literature suggests [4, 2], understanding multiliteracies requires time as it is really a different way of conceptualizing literacy. We think that the participant perspective of a cultural lens is a significant understanding of multiliteracies learning, and that provides a segue to another question we want to ask on how an educational worldview affects the task of teaching. This shall be highlighted further in our educational implications.

In summary, some participant responses indicated that there were opportunities and difficulties for implementing a multiliteracies perspective. Some responses indicated that creativity and flexibility to implement certain multiliteracies pedagogies was purposefully thought out. At other times participant interpretations of what it meant to implement a multiliteracies perspective fell short of the core understandings so that it was seen more as a strategy or as technology for helping teachers teach concepts. Some of the participants suggested that as first year teachers they are thinking about utilizing a multiliteracies pedagogy because it enhances differentiated and/or holistic learning within their classrooms. Specific references also occur from teachers using curriculum materials from more printbased practices to include other modes and media. Noted examples included images (like drawing), video, songs, tactile activities, blogging, and Instagram. Giving students choice in the modes and media they use for representing their ideas is motivating as teachers see students actively engaged in learning. Overall, there arose a distinction between teachers who saw multiliteracies as part of a cultural ecology for teaching in the classroom, and those who understood multiliteracies in fragmented aspects as either being a strategy or a way to include diversity as 'part' of curriculum, which served to be 'enough' in their reflection of learning and assessment. Similar themes have been found in the literature on the use of multimodal literacy pedagogy as discussed in research by Loerts [8]. In her research, multimodal literacy was seen as something to be negotiated into teaching for engagement purposes. The literature also documents the use of multimodal literacy as "a means to a print-centric end" [8]. This does not mean that print is not valuable, but it must be conceptualized within multiple modes of communication - each of which is considered equal in importance within a multimodal literacy framework. Both the research literature on the use of multimodal literacy learning in classrooms and the reflections from first year teachers echo how 
the enactment of curriculum from a multiliteracies perspective is still not engrained in pedagogy.

\section{Educational Implications}

Scant research has been done in following teacher candidates into their first years of teaching as they reflect on their opportunities to implement multiliteracies. In following these first year teachers we uncovered their theoretical understandings and the degrees to which their interpretations of multiliteracies extended into their teaching. The findings are a significant contribution to the research literature, building upon what Elliott-Johns [20] stated in her own research with teacher candidates. In speaking about multimodal ways of communicating, Elliott-Johns stated that educators need to foster "a beginning and not an end" of professional learning within what she calls a "teacher education continuum." [20] Our research has supported this view, in that teachers have a rudimentary understanding of multiliteracies in fragmented forms, but have not fully embraced it within a cultural ecology of learning that results in sound pedagogy. This may occur after more classroom experience is obtained.

One of the insights from this research has implications for future research and reflection by educators. Assessments of multimodal texts was something that the participants mentioned as being nebulous at times, although there were first year teachers who did look at assessment more holistically and looked at the process as well as the content. However, a general consensus among these first year teachers point to the fact that it is difficult to know what and how to assess from a multiliteracies perspective - most notably because of their interpretation of what multiliteracies pedagogies entailed. It stands to reason that this is an area of growth for both educators of teacher candidates and of first year teachers (and beyond). We suggest that teacher candidates need to understand the Ontario curriculum expectations as something that can be looked at more holistically so that multiliteracies learning is not subject specific, as some of our findings suggested. In that way teachers can connect learning from a multiliteracies perspective across the curriculum. When educators at all levels start thinking about what counts as literacy, assessment practices will need to reflect the expanding definitions of literacy to encompass multiple modes and media - something already echoed in the research literature $[11,5]$.

The proposed benefits of this research go beyond what these first year teachers will be able to gain through their engagement in teaching and learning through different modalities. The greater educational community also benefits from this research as the continued understanding of what multiliteracies learning entails becomes more developed and transformed through all levels of education. Specifically, we as educators have benefited from the insights of this research as we consider how to move forward with our own teaching. One of the things that we learned from this research is how to be responsive in our own teaching of multiliteracies in our teacher education program. With regard to assessment practices of multiliteracies, we take to heart what was previously mentioned about how assessment practiced need to reflect the kinds of multimodal texts that can be created (and interpreted) by students. From this we think it would be beneficial to us as well as other educators to incorporate more discussions about what modes are and what their affordances can be for communication. Then we apply the knowledge to examples and assignments which can then be further debriefed according to their interpretations of the kinds of learning that have taken place within a multiliteracies framework. This would be especially helpful to see how the students understand the theoretical basis for multiliteracies and we can refine ideas from there. Because we have seen resistance and misunderstandings in our research and classroom experiences about multiliteracies learning, we know that teachers also sometimes fall back on assessing what they have previously assessed: more printbased literacy practices. This is something that is echoed in the research literature [10] and is notably an area of growth to assure better understanding of multiliteracies pedagogy.

Furthermore, based on the findings of the research one other thing that we as educators have learned is to be more purposeful about how to assess texts that are multimodal and reflective of multiliteracies pedagogy. As we have described in this paper, some participants equated assessment with presentation instead of representation. Actually creating multimodal artefacts may be helpful for students so that they can use these as models for assessment practices that go along with these artefacts. It is with modelling, practice, talking about, giving and getting feedback and reflecting upon newer concepts that one becomes more familiar with the possibilities and constraints of communicating in multimodal ways. It is our hope that these insights may benefit other educators at every level of teaching so as to provide both theoretical grounding and practical applications of multiliteracies that will benefit teachers as they go out into their first year of teaching. We recognize that further data collection on the questions of this study would be purposeful for future research something we hope to continue. Further research ideas would be to look at how teachers' worldviews affects the task of teaching as theory and practice come together in classrooms.

In conclusion, we propose that the benefits of this research and the implications for further study would 
suggest that teacher education programs need to think about the longevity of what has been taught. We also suggest that further work will always need to be done to equip teacher candidates for the demands of literacy in the $21^{\text {st }}$ century. It is our hope that teachers, no matter how many years of experience they have, would have facility with modes and media. From there teachers can think about how their multiliteracies pedagogies fit within a cultural ecology of teaching and learning so that they will always be thinking about the complexities of literacy learning within an ever changing, multidimensional world.

\section{References}

[1] New London Group, "A Pedagogy of Multiliteracies: Designing Social Futures", Harvard Educational Review, 1996, pp. 60-92.

[2] C. Jewitt, and G. Kress, Multimodal Literacy, Peter Lang, New York, NY, 2003.

[3] Ontario Ministry of Education, "Literacy for Learning: The Report of the Expert Panel on Literacy in Grades 4 to 6 in Ontario", Queen's Printer, Toronto, ON, 2004.

[4] C. Jewitt, "Multimodal Discourses Across the Curriculum", In M. Martin-Jones, A.M. de Mejia and N. Hornberger (Eds.), Encyclopedia of Language and Education: Discourse and Education (2 ${ }^{\text {nd }}$ ed., pp. 357367). Springer Science +Business Media, Boston, MA, 2008.

[5] M. Walsh, "Multimodal Literacy: What Does it Mean for Classroom Practice?", Australian Journal of Language and Literacy, 2010, pp. 211-239.

[6] P. Albers, and J. Harste, "The Arts, New Literacies, and Multimodality", English Education, 2007, pp. 6-24.

[7] P. Stein, Multimodal Pedagogies in Diverse Classrooms: Representation, Rights and Resources, Routledge, London, UK, 2008.

[8] T. Loerts, "Multimodal Literacy Learning Opportunities in One Grade Six Classroom: Possibilities and Constraints" (2013). University of Western Ontario Electronic Thesis and Dissertation Repository. Paper 1735. http://ir.lib.uwo.ca/etd/1735.

[9] J. Cummins, "Multiliteracies and Equity: How do Canadian Schools Measure Up?", Education Canada, 2006 (Spring), pp. 4-7.
[10] A. H. Dyson, "Staying in the (Curricular) Lines: Practice Constraints and Possibilities in Childhood Writing”, Written Communication, 2008, pp. 119-159.

[11] P. Stein, "The Olifantsvlei Fresh Stories Project: Multimodality, Creativity, and Fixing in the Semiotic Chain", In C. Jewitt and G. Kress (Eds.), Multimodal Literacy (pp. 123-139). Peter Lang, New York, NY, 2003.

[12] K. Lenters, and K. Winters, "Fracturing Writing Spaces: Multimodal Storytelling Ignites Process Writing", The Reading Teacher, 2013, pp. 227-237.

[13] P. Whitin, "Forging Pedagogical Paths to Multiple Ways of Knowing”, English Education, 2006, pp. 123-145.

[14] K. Mills, "Shrek Meets Vygotsky: Rethinking Adolescents' Multimodal Literacy Practices in Schools", Journal of Adolescent and Adult Literacy, 2010, pp. 35-45.

[15] L. Handsfield, "Being and Becoming American: Triangulating Habitus, Field, and Literacy Instruction in a Multilingual Classroom", Language \& Literacy, 2006, pp. $1-26$.

[16] B. Glaser, and A. Strauss, The Discovery of Grounded Theory: Strategies for Qualitative Research, Aldine Publishing Co., Chicago, IL, 1967.

[17] D. E. Smith, "Institutional Ethnography: A Sociology for the People", AltaMira Press, Oxford, UK, 2005.

[18] R. K.. Yin, Qualitative Research from Start to Finish, Guilford Press, New York, NY, 2011.

[19] A. Burke, and R. Hammett, "Introduction: Rethinking Assessment from the Perspective of New Literacies", In A. Burke \& R. Hammett (Eds.), Assessing New Literacies: Perspectives from the Classroom (pp. 1-14). Peter Lang, New York, NY, 2009.

[20] S. Elliott-Johns, "Exploring Multimodal Literature Response with Pre-Service Teachers", Learning Landscapes, 2011, pp. 169-186. 